\title{
Apomorphine induced reinforcement
}

PAUL ROBINSON AND MARVIN DALEY, UTAH STATE UNIVERSITY

PETER C. WOLFF, STATE UNIVERSITY COLLEGE AT POTSDAM(N.Y.)

Under a $2 \mathrm{mg}$ per $\mathrm{kg}$ intraperitoneal injection of apomorphine, four female Long Evans hooded rats were placed on continuous and fixed ratio reinforcement schedules using a gnawable pine block. Ss would learn to turn their heads away from the gnawable object in order to obtain $15 \mathrm{sec}$. of gnawing time. The rate of response increased from less than one response in $5 \mathrm{~min}$. to over 3 responses per $\min$. in $101 \frac{1}{2} \mathrm{hr}$. conditioning sessions. Rates of response stabilized during the last 5 experimental sessions and fixed ratio schedules of up to $5: 1$ were obtained in five additional $11 / 2 \mathrm{hr}$. sessions.

A study by Ernst (1964) demonstrated that a gnawing syndrome could be induced in rodents with injections of apomorphine. Ernst considered the gnawing syndrome to be present when rats would gnaw the bottom of a wire cage for a period of $5 \mathrm{~min}$. and would return to gnawing the wire mesh after forceful removal. Weissman (1966) found that pigeons would exhibit floor pecking behavior under apomorphine. Pigeons which had previously been conditioned to peck a key at low rates for food would increase the rate of key pecking under apomorphine.
Preliminary studies in our laboratory indicated that apomorphine produced a tremendous compulsion to gnaw in rats. Intraperitoneal injections would produce Ss who would lick and gnaw to the extent of mouth bleeding. Virtually any object, including glass and sandpaper, would be sought out as a gnawable object for periods of $8 \mathrm{hr}$. after injection. The present experiment was conducted to see if gnawable objects would become reinforcing under the influence of the drug apomorphine.

\section{Method}

Four female Long Evans hooded rats, weighing from 240 to $290 \mathrm{gm}$ at 12 weeks, served as Ss. The Ss were injected intraperitoneally with $2 \mathrm{mg} / \mathrm{kg}$ of apomorphine which had been converted into a hydrochloride salt. Fifteen min. after injection, the Ss were placed into a steel restraining tube $2-1 / 4$ in. in diameter and $7-1 / 4$ in. long. The tube was mounted on a platform which was $5-1 / 4$ in. above the floor of the test chamber. The Ss were restrained in the tube so that they could not gnaw on their feet or tail but could still move their heads freely. A photoelectric

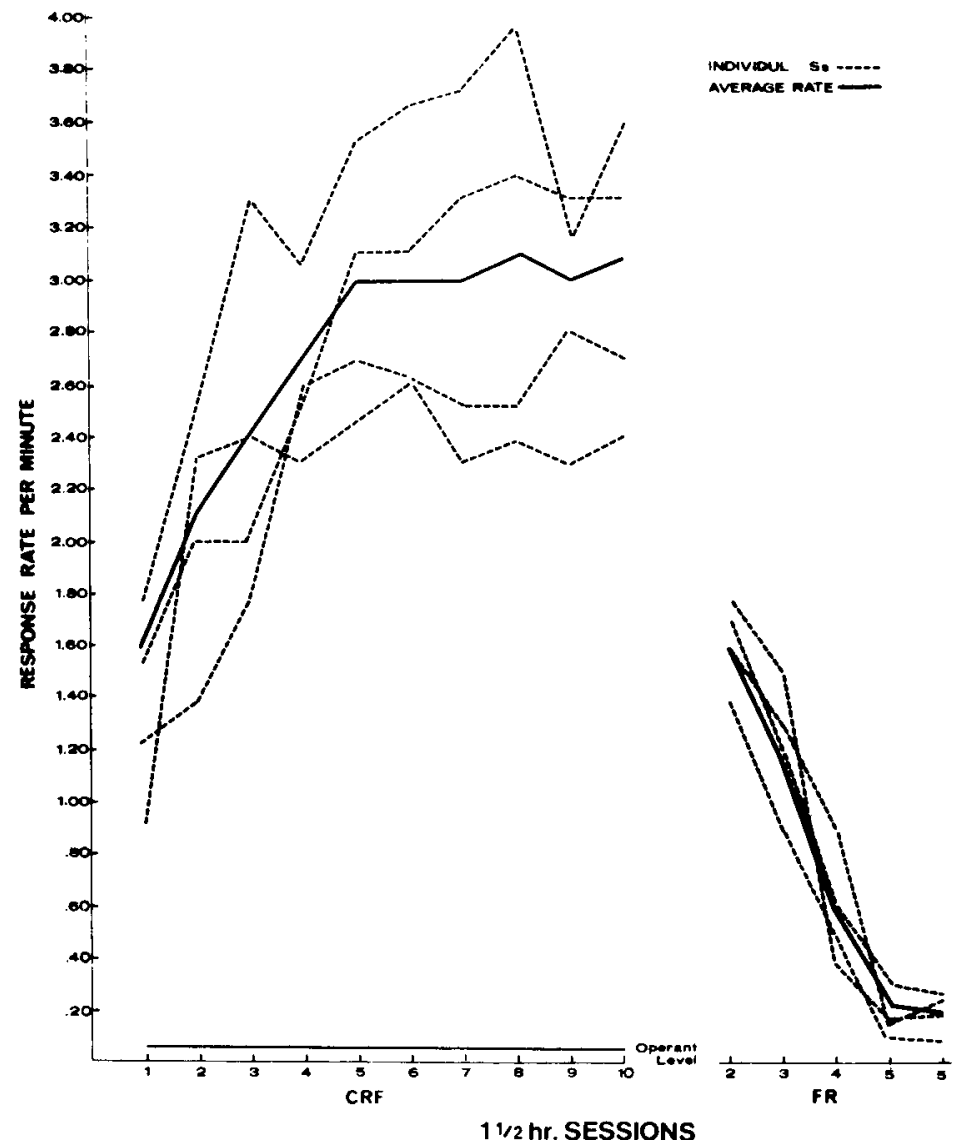

Fig. 1. Average and individual response rates for each $1 \frac{1}{2} \mathrm{hr}$. session under continuous reinforcement and fixed ratio schedules. Response rates are adjusted for time spent with the reinforcing object. 
beam was arranged so that an extreme head movement to the right would break the photoelectric beam and score a response on a counter. When a $\mathrm{S}$ broke the beam, he would receive access to a 1-1/2 in. $x 1-1 / 2$ in. $\mathrm{x} 2$ in. pine block for a period of $15 \mathrm{sec}$. A $12 \mathrm{v}$ light would come on when $\mathrm{S}$ broke the photoelectric beam in order to provide response feedback.

An operant level was obtained by placing Ss in the tube for three consecutive $1 \mathrm{hr}$. periods. During this time, no access to the gnawable object was provided. During a fourth training period, Ss were shaped to turn their heads to the right in order to gain access to the gnawable object on the left. Once a $\mathrm{S}$ began to break the photoelectric beam, a cumulative record was kept and each $S$ was run for 10 consecutive 1-1/2 $\mathrm{hr}$. sessions of continuous reinforcement. Then, fixed ratio schedules of $2: 1,3: 1,4: 1$, and $5: 1$, were attempted in five additional $1-1 / 2 \mathrm{hr}$. sessions.

\section{Results and Discussion}

Figure 1 presents the average operant level obtained for the four Ss. Figure 1 also illustrates the average and individual response rates for the $101-1 / 2 \mathrm{hr}$. conditioning sessions during which the Ss were continuously reinforced. Each $\mathrm{S}$ demonstrated a sharp increase of the head turning response during the first three conditioning sessions. The rate of this response stabilized during the final five sessions at over 3 responses per min. The $15 \mathrm{sec}$. periods spent with the gnawable object during each reinforcement period was not included in the calculating of the response rates. Thus, the average of 3 responses per min. represents the free operant rate.
Figure 1 also presents the results of introducing the fixed ratio schedules. Under the fixed ratio schedules, the rate of head turning decreased proportionally to the fixed ratio requirement; however, the rate of response during the fixed ratio schedules remained above operant level. Three satiated rats were tested in the restraining device to determine if the gnawable object had any reinforcing properties because of food and water deprivation time. No increase in gnawing was observed.

It can be concluded that for the rat, a gnawable object gains reinforcing properties under the influence of apomorphine. The effect seems to be a durable one since the operant rate stabilized and remained well above operant level during the last five $1-1 / 2 \mathrm{hr}$. sessions. Although there was a decline in rate under the fixed ratio schedules, the rate of response was still above operant level. The decline in response rate during the fixed ratio schedule was partially due to the long pauses the Ss manifested after a reinforcement period. This pause following fixed ratio reinforcement is typical of this type of schedule.

\section{References}

Emst, A. M. Relation between the action of dopomine and apomorphine. Psychopharmacology, 1965, 7, 391-399.

Weissman, A. Apomorphine elicitation of key pecking in pigeons. Arch. int. Pharmacodyn. Ther., 1966, 160, 330-334.

\section{Note}

1. This study was based on a Master's Thesis by the first author. The authors wish to thank Frank Stermitz for many valuable suggestions. Support for the study was obtained from the Utah State Uniform School Fund 235. 